\title{
Análise de textos multimodais em capas de materiais didáticos de Português LE/L2
}

\author{
Giuliano Pereira de Oliveira Castro \\ Universidade Federal de Goiás \\ professorgiuliano@gmail.com
}

\begin{abstract}
Resumo
O ensino de línguas é norteado pela concepção acerca da natureza da linguagem, seu funcionamento e função nas práticas sociais, bem como das concepções e dos postulados sobre como se deve ensinar e aprender línguas. O escopo da pesquisa em Linguística Aplicada é bastante amplo no que tange à natureza dessa concepção, denominada abordagem, presente em todas as esferas do complexo processo de ensino e aprendizagem de línguas, e uma dessas esferas é o material didático. Grandes mudanças nos paradigmas de ensino de línguas bem como o advento de novas tecnologias têm transformado o material didático, conferindo-lhe cada vez mais uma natureza multimodal (vários modos semióticos para produção de significado). Nosso enfoque neste trabalho é a investigação acerca da relação existente entre a multimodalidade textual presente nas capas de três materiais didáticos para ensino de Português para estrangeiros publicados no Brasil e a abordagem que subjaz a esses materiais, tendo em vista os textos multimodais como enfoque e ponto de partida. O estudo evidencia a natureza multimodal da linguagem e conclui que um foco mais intenso na abordagem comunicativa, com ênfase nos processos de interação, requer que texto (linguagem verbal) e imagem (não verbal) sejam combinados de forma que promovam um contexto comunicativo profícuo.
\end{abstract}

Palavras-chave: Material didático. Multimodalidade. Abordagem.

\begin{abstract}
Language instruction is guided by the conception of the nature of language, its function and role in social practices, as well as conceptions and postulations about how one should teach and learn languages. The scope of research in Applied Linguistics is quite broad concerning the conception of that nature, known as approach, present in all spheres of the complex process of teaching and learning languages. One of those spheres is instructional materials. Major changes in the paradigms of language teaching as well as the advent of new
\end{abstract}


technologies have transformed teaching materials, attributing them an increasingly multimodal nature (several semiotic modes for the production of meaning). Our focus on this paper is to research the relationship between the textual multimodality present in three coursebook covers for teaching Portuguese to foreigners published in Brazil, and the approach that underlies these materials, having the texts as our multimodal focus and starting point. The study highlights the multimodal nature of language and concludes that a more intense focus on the communicative approach, with emphasis on interaction processes, requires that text (verbal language) and image (non verbal) are combined to promote a meaningful communicative context.

Keywords: Language teaching materials. Multimodality and foreign language teaching. Approaches.

\section{Globalização, multimodalidade e ensino de línguas}

Vivemos hoje em um mundo globalizado, onde as informações são passadas adiante em velocidade incrível. As novas tecnologias têm modificado os processos de interação, de forma que a distinção entre o local e o global está cada vez mais diluída. Segundo Bauman (1999), o local, ou seja, as práticas sociais características de determinadas culturas, está cada vez mais sendo sobreposto pelo global, que trata da conjuntura econômica capitalista responsável por disseminar mundo afora a música, a comida, os produtos industrializados e tudo o que interessa para o lucro das multinacionais.

As novas tecnologias que vêm sendo aperfeiçoadas, sobretudo a partir da década de 1990, têm influenciado as práticas sociais de todo o mundo. Muitas práticas tornam-se obsoletas, outras são reformuladas para atender às demandas de um mundo globalizado onde as mercadorias (e as informações) precisam ser difundidas de forma rápida e eficiente. Nesse contexto, é um tanto óbvio afirmar que a vida cotidiana tem sido influenciada pelas mudanças inseridas pelas novas tecnologias, sobretudo a internet, cuja principal característica, segundo Bauman (1999), é anular as distâncias, transformando a forma como as pessoas interagem.

As mudanças nos processos de interação e de troca de informações promovem o que Bauman chama de mobilidade, ou seja, um processo de movimento ainda que se esteja imóvel fisicamente. Tal mobilidade permite um transporte dinâmico de informações, 
promovendo um tipo de comunicação sem movimento dos corpos físicos, consentindo que a informação viaje independentemente de seus portadores físicos. Toda informação é permeada de ideologias, isso porque, em aquiescência com Fairclough (2003), afirmamos que informação é linguagem, cuja natureza tem uma relação direta com relações de poder e ideologia. Voltando ao conceito de globalização, é importante ressaltar que tal processo altera as práticas de consumo e exerce influência nos costumes e nos aspectos culturais, tais como na moda, na música, influenciando diretamente a vida das pessoas e, com isso, a linguagem, meio pelo qual o mundo é construído em significado.

Ainda segundo Dionísio, "as ações sociais são fenômenos multimodais" (2006, p. 133). Isso porque a interação requer que se utilize mais de um recurso para a produção de significado e intercâmbio de informações. Todas as culturas produzem imagens, símbolos que lhes são característicos. As imagens, assim como a linguagem verbal, são carregadas de ideologias e são constitutivas das identidades. Celulares que funcionam como câmeras fotográficas, enviam e recebem mensagens, têm conexão com a internet; sem falar nos computadores, que ampliaram muito as formas de produção de imagens, bem como a veiculação destas. A produção de textos multimodais é cada vez mais recorrente. A televisão, por exemplo, foi bastante aprimorada, adquiriu cores mais vivas, imagem mais nítida, e seu conteúdo é vendido em várias partes do mundo. A imagem se funde com o verbal e constrói novos sentidos discursivos (VIEIRA, 2007).

Uma prática bastante recorrente desde os primórdios (e acentuada com o fortalecimento da globalização) é o ensino de línguas, sejam maternas ou estrangeiras. $\mathrm{O}$ mundo globalizado é um celeiro de propagação e divulgação de culturas (e das práticas que as constituem), e a linguagem é o meio pelo qual as ideologias são reforçadas, transmitidas e enfatizadas, criando imagens, estereótipos que constituem a identidade de um povo.

O ensino de línguas é cada vez mais necessário e difundido, pois o mundo globalizado requer cada vez mais o domínio de uma língua estrangeira - LE (do inglês, sobretudo). Portanto, é necessário situar nossa pesquisa no escopo das pesquisas em Linguística Aplicada (doravante LA) que atualmente lida com questões concernentes à 
linguagem inseridas em uma prática social (ALMEIDA FILHO, 2006). Assumir tal concepção como ponto de partida para estudos aplicados na área da linguagem é atentar para o fato de que a linguagem é realizada socialmente, é constitutiva das identidades, molda e restringe as relações de poder, bem como é o meio pelo qual o mundo é constituído em significado.

A pesquisa em LA, segundo Moita Lopes (2006), deve ser focalizada sobretudo na compreensão das práticas sociais nas quais são inseridos os participantes da pesquisa, o que implica ir além do estudo de um fenômeno como a relação entre teoria e práxis de um professor em sala de aula, com enfoque na análise de sua abordagem de ensino. Deve-se ter em mente que cada sujeito envolvido no processo de ensino e aprendizagem tem uma história, é oriundo de práticas sociais diversas, convergentes ou não, as quais interferem no processo e devem ser levadas em consideração para análise da práxis do professor. Conforme já explicitado, a linguagem recebe influências diversas das práticas sociais que a permeiam, portanto o material didático é um reflexo disso, uma vez que se observa uma tendência contemporânea de utilização de textos retirados dos meios de comunicação, como jornais, revistas, internet, televisão, entre outros. Isso tem refletido diretamente na elaboração de material didático (MD) para ensino de línguas, uma vez que o MD é muitas vezes a primeira forma de contato que o aprendiz tem com a LE, bem como com a cultura do(s) povo(s) falante(s) da(s) língua(s)-alvo.

É sabido que o MD constitui parte importante do processo de ensino-aprendizagem de línguas e que nele devem estar contidas informações culturais, bem como linguísticas. Em muitos casos, o MD constitui a principal fonte de insumo na sala de aula. Analisá-lo é uma tarefa que requer atenção aos diversos aspectos que o compõem, pois sua elaboração, distribuição e utilização são processos bastante complexos. Pretendemos, com este trabalho, analisar o MD voltado ao ensino de PLE, a saber, as capas de forma mais pormenorizada e algumas páginas componentes dos MDs analisados e tratar das relações entre a multimodalidade dos textos e a abordagem que subjaz esses textos. Nosso enfoque não é prover uma análise pormenorizada dos MDs de PLE, mas sim, por meio das capas, ter um norte, uma noção de como os textos multimodais funcionam e como interagem para a produção de significados. 
Acerca da abordagem, Almeida Filho (2005) a define como a filosofia de ensinar, a verdadeira força potencial que orienta, em larga escala, o processo de ensinar uma nova língua. Grosso modo, são as crenças, as ideologias, as noções e os pressupostos que regem a ação do professor de línguas em todas as esferas, desde o planejamento de cursos e aulas até a elaboração e a utilização de material didático.

\section{A natureza do texto multimodal e a gramática visual}

Hoje em dia, "vivemos em culturas que são cada vez mais permeadas por imagens visuais, imagens essas que têm uma variedade de intenções e efeitos programados" e, consequentemente, "todos os dias praticamos o olhar para tentar entender o mundo" (STURKEN; CARTWRIGHT, 2001, p. 10). As imagens fazem parte de quase todos os textos que usamos na vida diária, seja no campo pessoal, seja no profissional ou no acadêmico, e, de acordo com Kress, "agora é impossível compreender os textos, até mesmo suas partes linguísticas somente, sem ter uma ideia clara de como esses outros elementos podem estar contribuindo para o significado do texto" (KRESS, 2000, p. 337). Conforme Descardesi (2002, p. 20),

Qualquer que seja o texto escrito, ele é multimodal, isto é, composto por mais de um modo de representação. Em uma página, além do código escrito, outras formas de representação como a diagramação da página (layout), a cor e a qualidade do papel, o formato e a cor (ou cores) das letras, a formatação do parágrafo, etc. interferem na mensagem a ser comunicada. Decorre desse postulado teórico que nenhum sinal ou código pode ser entendido ou estudado com sucesso em isolamento, uma vez que se complementam na composição da mensagem.

Mas a despeito dessa grande mudança, ainda hoje "pouca atenção é dada à imagem em textos que fazem parte de nossa aprendizagem formal, ou mais precisamente, as imagens encontradas em livros didáticos" (HEMAIS, 2006).

Mayer define a multimodalidade (que ele intitula multimedia) nos gêneros discursivos escritos como: 
[...] a apresentação de um material usando palavras $e$ imagens. Por palavras, eu quero dizer um material que é apresentado na forma verbal, tais como textos escritos ou orais. Por imagens, eu me refiro ao material que é apresentado na forma pictórica, tais como os que fazem uso de gráficos estáticos, incluindo ilustrações, tabelas, fotos, ou mapas, ou os que usam gráficos dinâmicos, que incluem animação ou vídeo (MAYER, 2001, p. 2, grifo nosso).

Kress e Van Leeuwen defendem que "o componente visual de um texto é uma mensagem organizada e estruturada independentemente - ele é conectado com o texto verbal, mas, de jeito algum, dependente dele: e similarmente o oposto também é válido" (1996, p. 17). Em outras palavras, os modos semióticos da linguagem e da imagem coexistem em gêneros discursivos escritos, porém podem ter funções independentes e específicas. Kress acredita que

[...] os modos semióticos da escrita e da imagem são distintos no que eles permitem fazer, ou seja, nas suas affordances. A imagem se fundamenta na lógica da exposição no espaço; a escrita (e a fala ainda mais) se fundamenta na lógica da sucessão no tempo. A imagem é espacial e não seqüencial; a escrita e a fala são temporais e seqüenciais. Esta é uma diferença profunda, e as suas conseqüências para a representação e a comunicação estão começando a emergir nesta revolução semiótica. Um dos efeitos é a especialização da fala, da escrita, e da imagem, na qual cada um desses modos é usado para fazer o que ele faz de melhor. Nesta especialização, a linguagem não é mais a fonte de todo o significado (KRESS, 2000, p. 339).

Sabe-se que uma imagem vale mais que mil palavras, e aquilo que se vê tem mais impacto do que aquilo que se lê ou ouve. A título de exemplo, tomemos o caso dos trabalhadores do Movimento dos Sem Terra (MST) mortos em confronto com a polícia no município de Eldorado dos Carajás, Estado do Pará, em 1996. 


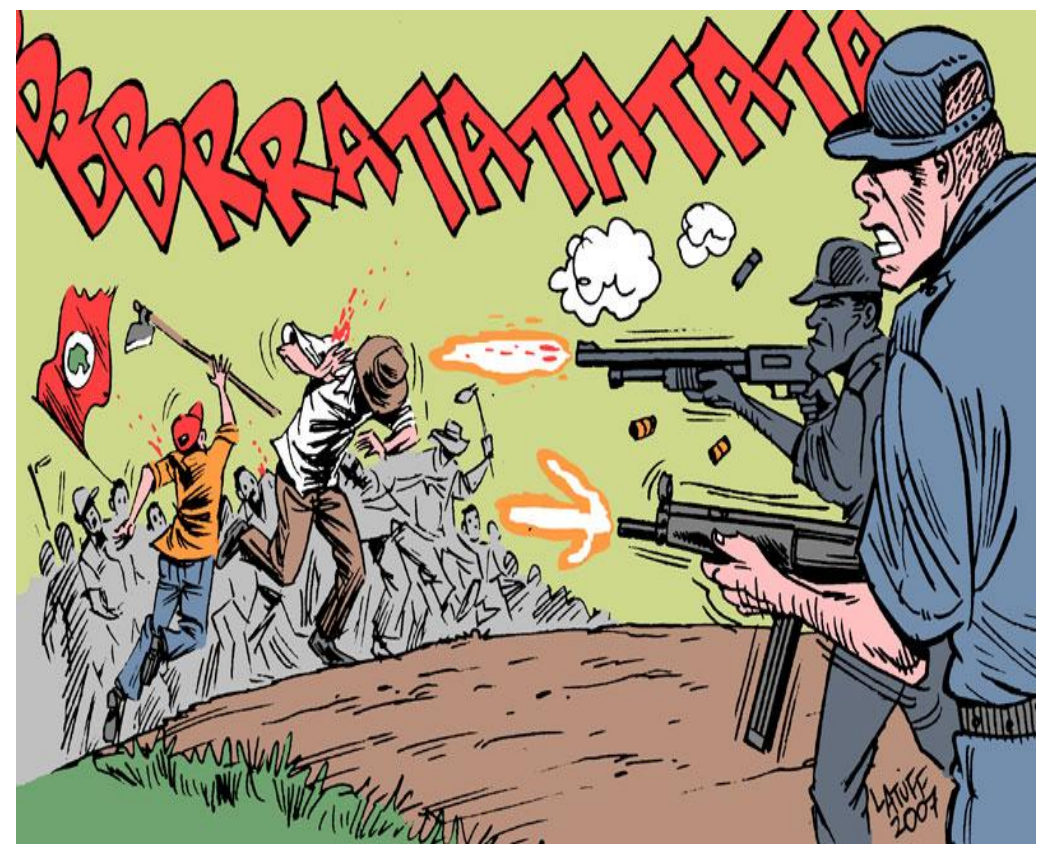

Figura 1: Eldorado dos Carajás

Fonte: 〈http://blogsimpa.zip.net/images/Eldorado_by_Latuff.jpg> Acesso em: 4 jun. 2016.

Como já dito, a imagem impõe domínio próprio, dada sua relevância no mundo contemporâneo, e o apelo visual envolve o leitor (chamado de viewer por Kress e Van Leewen). Os participantes são postos em relação de interação, mediada por desigual relação de poder, status social diferente, além de forte demonstração ideológica do produtor do texto. Todas essas características são também encontradas na análise de questões ideológicas presentes na linguagem verbal (escrita e oral).

Categoria dos participantes representados: meninas dançando, conversando e elementos que representam tanto o subúrbio ao qual a autora se refere (o sobrado mal acabado) quanto a boa escola (com boa estrutura, paredes pintadas). 
Aqui se observa que a imagem representa cenas reais e cotidianas da autora, mas a escolha dos participantes e o modo com que eles estão representados não são neutros. Percebe-se que o produtor do texto quis enfatizar a diferença dos grupos não só pela modalidade escrita, mas também pela gramática visual. Isso pode ser visto pela maneira com que as fotografias estão dispostas e pelo fundo contrastante de ambas, que revelam construções e condições diferentes.

Categoria do processo narrativo reacional: as setas mostram que as participantes (reacters) estão interagindo entre si - tanto na dança quanto na conversa o olhar é direcionado para outro agente.

Os aspectos ideológicos que permeiam os textos multimodais podem vir a ser naturalizados na fala do aluno caso o professor não realize um trabalho adequado com esse tipo de texto. Cabe ao docente apresentar aos alunos diferentes visões de mundo, que são trabalhadas com o auxílio dos livros didáticos e que os auxiliam na formação de crenças e valores. Por esse motivo, o professor de LE deve ter consciência da importância do trabalho estruturado e apresentar textos de natureza diversa, evitando assim o reforço de determinados estereótipos sobre a cultura brasileira pelos alunos.

\section{Análise de material didático de Português como Língua Estrangeira}

Segundo Kress e Van Leeuwen (1996), as imagens presentes num texto multimodal não têm somente valor estético e coadjuvante, mas refletem também a sociedade em que o texto foi produzido e suas diferenças, interesses e incongruências (p. 18). Dessa forma, aprender a analisar imagens que aparecem em revistas, publicidades, matérias jornalísticas e mesmo no livro didático pode auxiliar o aluno a "ler por entre as linhas" e perceber nelas mensagens implícitas que, na maioria das vezes, passam despercebidas ao leitor comum.

O material didático para ensino de LE é, ou pelo menos deveria ser, uma rica fonte de textos multimodais em que a imagem desempenha papel crucial na produção de significado. Tomemos como exemplo um aprendiz iniciante de alguma LE sem muito conhecimento acerca da cultura do(s) país(es) falante(s) daquela língua. A esse respeito, Silveira (1998) acrescenta: 
Progressivamente também se verificou-se que era necessário, ao se ensinar línguas para estrangeiros, que se atendesse aos fins específicos que levaram o aluno a procurar aprender uma nova língua às suas reais dificuldades de aprendizagem. Para tanto, foi realizada uma reformulação teórica e metodológica a fim de se propor um ensino de línguas estrangeiras, privilegiando-se a interação comunicativa.

As representações sociais presentes no MD compõem parte da identidade daquele povo e de sua cultura, suas práticas sociais, bem como do reforço ou não de estereótipos culturais. O espaço onde se aprende uma LE torna-se um jogo de identidades e de conflitos culturais (no caso do ensino de PLE). Como bem observa Mendes (2002), ensinar Português do Brasil é mais do que ensinar uma língua, "é responder ao desejo daquele que quer se fazer outro, ao construir-se ele próprio; é abrir as portas" (s.n.). Lidar com esse jogo de identidades e culturas é desafiador, e o MD deveria auxiliar nesse processo na medida em que oferece ao aprendiz não apenas pontos importantes acerca da nossa língua, mas também da nossa cultura, de quem somos, de como vivemos e interagimos.

\section{Multimodalidade textual e material didático de PLE}

Field (2004) afirma que os componentes visuais ou imagéticos exercem diversas funções na vida cotidiana, entre elas destacamos a capacidade de ativar conhecimentos anteriores; esquematizar os pontos principais e secundários do texto; resumir informações; enfatizar os pontos centrais; organizar itens em uma lista, oferecer reforço visual para o assunto; explicar visualmente um conceito por meio de fotografia, gráfico ou diagrama; apresentar informações suplementares; apresentar um resumo dos assuntos principais. Todas essas funções apresentadas são importantes, pois podem funcionar como facilitadoras do processo de aprendizagem de línguas, pois a imagem remete a um conceito, um significado, que remete a algo na mente, um conhecimento prévio. 
Embora importantes, as funções não dão conta da natureza da estrutura da imagem, como ocorre com as metafunções propostas por Kress e Van Leeuwen (1996; 2000). Passaremos agora a analisar os MDs publicados para o ensino de PLE no Brasil, a saber, Diálogo Brasil, curso intensivo de português para estrangeiros (IUNES, LEITE; LIMA, 2003); Português via Brasil: um curso avançado para estrangeiros (LIMA; IUNES, 2005) e Bem-vindo! A língua portuguesa no mundo da comunicação (PONCE; BURIM; FLORISSI, 2004). A escolha dos MDs a serem analisados seguiu dois critérios básicos: a) o ano de publicação ou reedição do MD, pois tivemos como enfoque a análise de materiais recentes, publicados sob os parâmetros das novas tecnologias; e b) a forte presença de imagens, fotos e outros recursos que compunham o MD. O enfoque de nossa análise, entretanto, não resvala para outros materiais multimídia, como CDs de áudio, por termos na imagem e na sua composição como outras semioses o enfoque desta análise.

As mudanças pelas quais passaram os materiais didáticos de LE nas últimas décadas trouxeram reestruturações quanto à composição textual das partes constitutivas das capas de livros didáticos, que, por apresentarem estruturas fixas, podem ser consideradas um gênero discursivo.

Outro ponto revelador sobre essas estruturas fixas é a comprovação da existência de um "código de integração", que implica uma sincronização de elementos por meio de um ritmo comum (VAN LEEUWEN, 1985, apud KRESS; VAN LEEUWEN, 2001), mesmo vivendo uma era de pluralidade de usos da linguagem. Dessa forma, meu enfoque, para o momento, volta-se ao conjunto dos modos semióticos envolvidos na produção dessas capas. Observemos as três capas que constituíram os dados empíricos desta pesquisa. 
Giuliano Pereira de Oliveira Castro

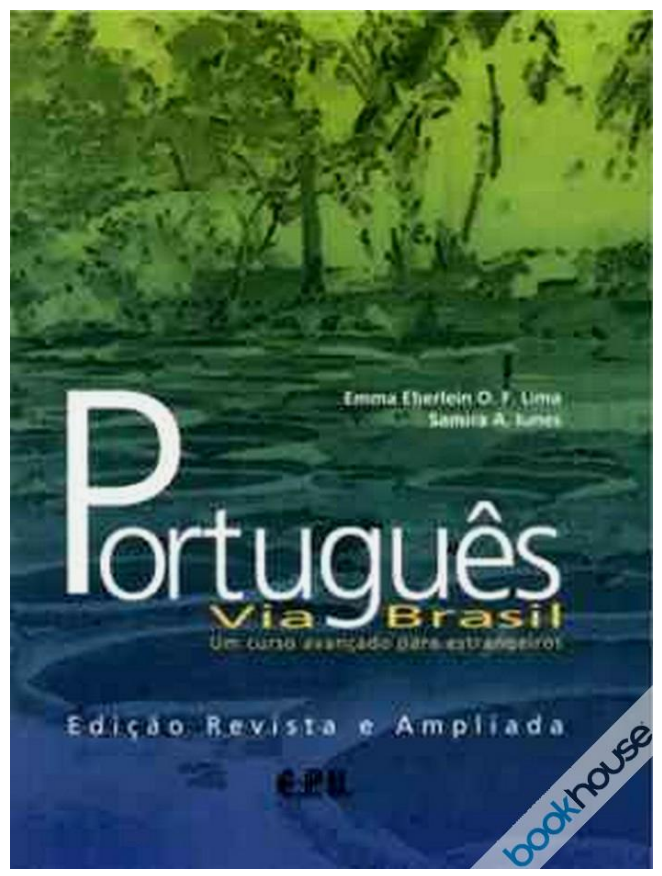

Figura 2: Capa de Lima e Iunes (2005)

Ao analisar as capas dos livros didáticos selecionados, pudemos verificar que alguns itens significativos se repetem nesse gênero e passam a ser as partes fixas de composição textual, são elas:

i) Título da série: Via Brasil.

ii) Nome dos autores: Emma Eberlein O. F. Lima e Samira Abirad Iunes.

iii) Título do livro: Português: um curso avançado para estrangeiros.

iv) Editora: EPU.

Em primeiro plano, temos o título da obra Via Brasil Português: um curso avançado para estrangeiros, com destaque para as palavras Via Brasil e Português. Os nomes das autoras, apesar de 
aparecerem antes do título, encontram-se em segundo plano, juntamente com o nome da editora.

$\mathrm{Na}$ modalidade imagética, existem poucos elementos representativos ou formas de expressão que remetam ao conjunto de aspectos que será apresentado no interior do livro. O que destacamos, nessa modalidade, são as cores do segundo plano: verde e azul (água) remetem à vegetação do Brasil como país tropical, as folhas e as árvores sombreadas reforçam a presença de florestas no país.

A primeira edição do livro data de 1990, e as mudanças aplicadas 15 anos depois na edição mais recente não são muito significativas no que concerne à representação de imagens, tampouco da composição de sentido entre o verbal e o não verbal. Não se trata de criticar o MD que não se encaixe em determinada perspectiva ou abordagem, mas sim perceber como os MDs de PLE lidam com a composição multimodal dos textos que os compõem. Como observamos no decorrer do MD, a presença de cores é quase nula. Com exceção das páginas 142 a 146 (pintura brasileira), todo o restante do livro (no total de 219 páginas) é monocromático.

A ausência de cor, segundo Kress e Van Leuwen (1996), é desmotivadora para a leitura de textos multimodais na pósmodernidade. As cores são representativas do mundo, dos significados, das relações de poder e das estruturas sociais. Até hoje o vermelho é conhecido como a cor do comunismo, mesmo duas décadas após a queda da União Soviética. Os times de futebol têm suas cores, e as camisetas com a cor de cada time e seu respectivo símbolo ou brasão identificam os membros daquela torcida, daquele grupo social que partilha a mesma prática social. As culturas latino-americana e brasileira também são conhecidas pelas cores vibrantes, que remetem ao tropicalismo, à pluralidade da sociedade, à alegria.

Embora a representação da mata tenha a ver com um traço da identidade brasileira, a representação feita na capa do referido livro não visa a representá-la de forma que o leitor possa fazer grandes associações. Observemos a figura seguinte, a qual traz a capa da edição de 1990 do mesmo livro. 


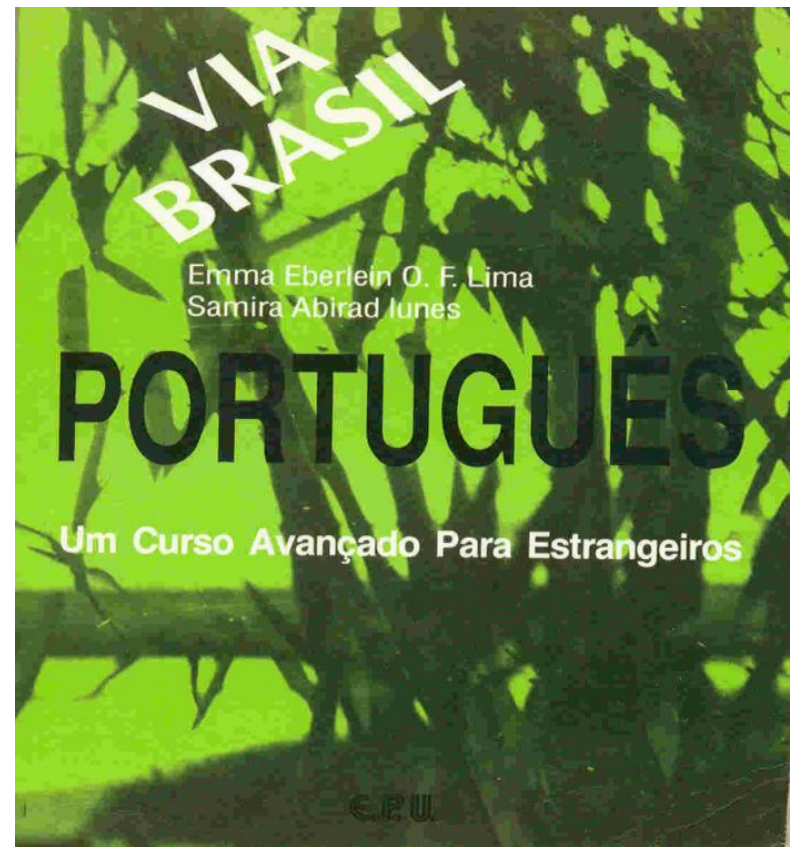

Figura 3: Capa de Lima e Iunes (1990)

Notemos que, 15 anos depois, o acréscimo da cor azul na capa deu um tom de contraste entre a água dos rios e o verde da floresta. $\mathrm{O}$ contraste amplia a noção de espaço, da realidade representada, embora não haja nenhuma ação transacional na capa, ou seja, nenhuma proposta de ação com base na imagem representada. No interior do livro, as páginas são em cor azul (as imagens produzidas para ilustração) e preto (cor predominante dos textos). Mesmo a edição de 2005 não demonstra grande preocupação em relacionar cor, imagem e texto para produzir significado.

A pouca combinação de cores é também notada no material seguinte, de Lima, Iunes e Leite. Observemos a capa. 


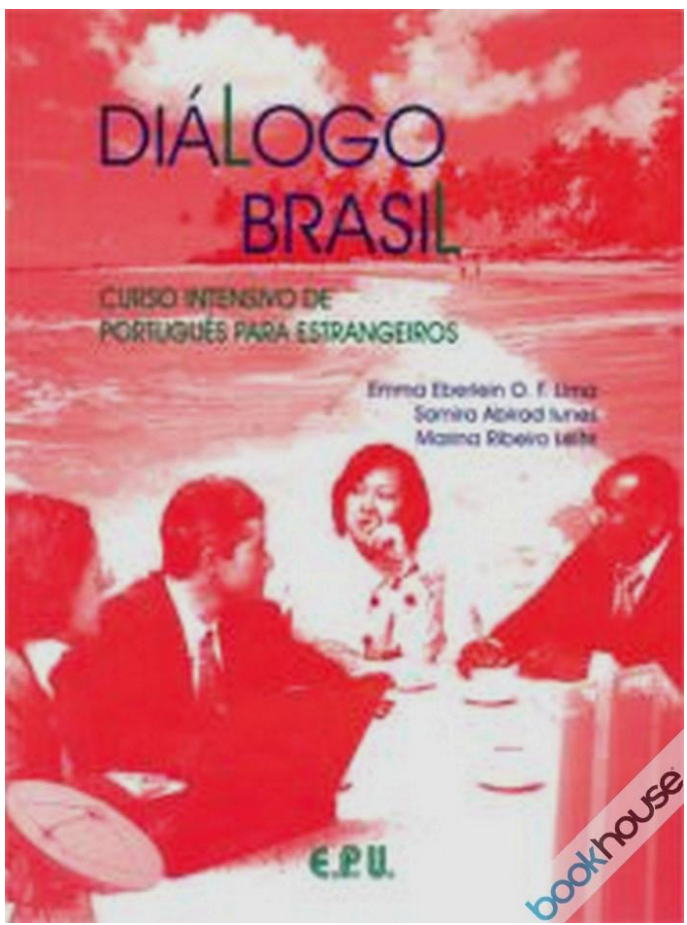

Figura 4: Capa de Lima, Iunes e Leite (2003)

i) Título da série: Diálogo Brasil.

ii) Nome dos autores: Marina Ribeiro Leite, Emma Eberlein O. F. Lima e Samira Abirad Iunes.

iii) Título do livro: Diálogo Brasil: curso intensivo de português para estrangeiros.

iv) Editora: EPU, 2005.

Em primeiro plano, temos o título da obra Diálogo Brasil: curso intensivo de português para estrangeiros, com destaque para as palavras Via Brasil e Português. Os nomes das autoras, apesar de aparecerem antes do título, encontram-se em segundo plano juntamente com o nome da editora. Eis que o padrão de organização das capas é mantido, parece haver similaridade quanto a esse aspecto. 
$\mathrm{Na}$ modalidade imagética, há maior representação de participantes. Na capa do MD anterior não foi possível identificar interação entre participantes representados, o que não acontece nesta. Os participantes são empresários estrangeiros que precisam da língua portuguesa para viver no Brasil. Eles se encontram na parte de baixo da página, sobrepostos por praias e belezas naturais do Brasil. A praia ocupa o primeiro plano por retratar uma realidade brasileira a ser representada, a de país tropical, bonito, que envolve as pessoas. Os brasileiros, nativos, encontram-se na praia, e os executivos estrangeiros estão trabalhando em um ambiente urbano representado pelo edifício espelhado no canto direito da página e pela antena no canto esquerdo. Ainda acerca da categoria dos participantes representados, podemos notar que todos os participantes estão ligados por um vetor que une os executivos pelo olhar e une estes aos brasileiros por meio da praia, da onda do mar, que interage com todos os participantes.

As cores azul e verde, cores da bandeira brasileira, também enfatizam os aspectos da realidade do país na qual esses profissionais estão imersos, trabalhando, enquanto ao seu redor há todo um mundo natural e tropical a ser explorado. O computador aberto sobre a mesa dá uma ideia de informação e trabalho, e a saliência (destaque) que ele ocupa na imagem lhe confere quase uma fusão ao participante do sexo masculino sentado em frente ao computador. Tudo isso significa que aqui no Brasil, além de um lugar onde se pode trabalhar, o estrangeiro encontra também um país bonito e cheio de atrativos naturais a serem explorados.

O framing (enquadramento), a disposição dos modos semióticos da capa também são um fator de composição de significados. Enquanto o primeiro plano é ocupado por quatro personagens principais, o segundo plano, que serve de moldura e atua de forma conjunta, possui pistas dos elementos culturais do país representados por meio de um ponto turístico - uma praia.

O MD moderno utiliza cores em grande escala, mas só esse excesso não chega a demonstrar preocupação com a junção dos elementos para a produção de significado. As cores são representativas assim como as imagens, mas é por meio das imagens que as representações tomam forma. Analisemos a próxima capa. 
Análise de textos multimodais...

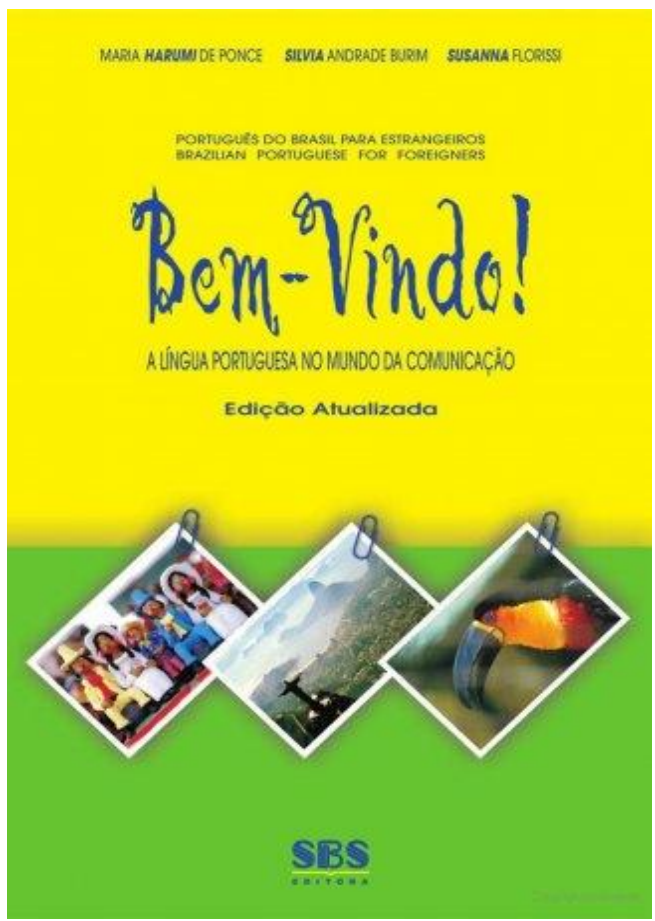

Figura 5: Capa de Ponce, Burim e Florissi (2004)
i)
Título da série: Bem-vindo!
ii) Nome dos autores: Maria Harumi de Ponce, Silvia Andrade Burim e Susanna Florissi.
iii)
Título do livro: A língua portuguesa no mundo da comunicação.

iv) Editora: SBS, 2004.

Seguindo o padrão das capas anteriores, o nome do livro fica em evidência, em destaque em relação às outras representações e modos semióticos. Os nomes das autoras, apesar de aparecerem antes do título, encontram-se em segundo plano juntamente com o nome da editora. 
$\mathrm{Na}$ representação imagética, a escolha dos participantes representados foi feita de forma que se privilegiassem imagens que representam a cultura e a identidade do povo brasileiro, verdadeiros ícones da nossa cultura, tanto dentro do Brasil quanto no exterior, a saber, o artesanato, a cidade do Rio de Janeiro e o tucano, ave típica de florestas tropicais. Ao contrário da capa anterior, não existem vetores ligando os participantes, que estão sobrepostos ao verde, cor marcante da bandeira brasileira, representativa das matas, da abundância de nossa vegetação. Há o amarelo, outra cor da nossa bandeira, que identifica a camisa oficial da seleção brasileira de futebol. Sobre o amarelo está escrito Bem-Vindo, título do livro e que remete também à hospitalidade do povo brasileiro.

Apesar de as imagens do artesanato, da cidade do Rio de Janeiro e do tucano (uma das aves símbolo do mundo tropical) não ocuparem grande espaço na capa do livro, ocupam papel de destaque no enquadramento da página, postas do centro para baixo, envoltas em uma linha branca chamada por Kress e Van Leuuwen (1996) de saliência (traços e marcas que destacam uma imagem).

\section{Abordagem e multimodalidade}

A disposição das imagens, sua escolha e os tipos de produção podem dar pistas preciosas quanto à natureza da abordagem de um MD. Nas páginas 2 e 3 do livro de Iunes e Lima (2005), por exemplo, a presença de um texto retirado de um jornal confere a autenticidade do material, ou seja, este não foi produzido exclusivamente para o MD. Tal característica é naturalmente conferida à abordagem comunicativa. $\mathrm{O}$ texto tem como tema "o tiro sair pela culatra" e enfatiza as armadilhas e os problemas que a sociedade pós-moderna enfrenta em decorrência de fatos e invenções que, em princípio, tinham o propósito de facilitar a vida moderna.

O campo lexical é bastante amplo, mas é pouco trabalhado. Há um quadro para trabalhar estruturas gramaticais sem que o contexto seja explorado. As imagens presentes no texto, embora componham significado com ele, apenas ilustram, isto é, exemplificam. Compor significado não quer dizer apenas ilustrar, mas delinear, demonstrar, enfatizar. Um exemplo é a capa do livro de Lima, Iunes e Leite (2003), 
cuja disposição de imagens remete a um significado e não apenas a uma ilustração ou exemplificação do que está representado pela linguagem verbal.

As duas imagens presentes no texto não são relacionadas uma a outra, a não ser pela forma arredondada que lhes é conferida, e seu conteúdo, embora represente participantes, não os relaciona por meio de um vetor que contextualize os participantes em um mesmo contexto.

A abordagem que identificamos como predominante no referido material é gramaticalista. Obviamente que apenas a presença de imagens e cores não é suficiente para identificação de uma abordagem, pois não basta colocar recursos imagéticos, é importante situá-los num contexto comunicativo em que a imagem ocupa papel importante para criar, suscitar discussão e interação (condições inerentes à abordagem comunicativa). As imagens são pressuposto para uma comunicação efetiva no âmbito do MD, pois se aprende melhor por meio de palavras e imagens de que apenas por meio de palavras. O que se observa é que quando palavras e imagens correspondentes são apresentadas próximas a tendência é o leitor assimilá-las e associá-las.

No livro de Ponce, Burime Florissi, como explicitado na página 13, as imagens e as cores dispostas na página seguem um padrão de organização, havendo relação entre imagem e texto ao se trabalhar o vocabulário referente a legumes e verduras. No entanto, esse contexto não se aplica ao tema central da unidade, que trata de pronomes, conjunções e pretérito perfeito do modo indicativo. Não há contextualização entre os tópicos da página, e as imagens não se relacionam num contexto comunicativo. A foto que vem ao lado do texto "Meu passado meu presente" não demonstra ser de brasileiros natos, tampouco a paisagem parece ser de algum lugar do Brasil. Sem essa preocupação com a disposição imagética em um contexto cultural, histórico e social, uma imagem não pode ser relacionada à comunicação efetiva, pois seu caráter é meramente ilustrativo.

A disposição de cores na página é para privilegiar os verbos conjugados no pretérito perfeito do indicativo, foco da unidade. O livro é bastante utilizado no ensino de PLE e, em princípio, parece ser embasado na abordagem comunicativa e apresenta textos sobre o cotidiano e curiosidades a serem exploradas de várias maneiras. A 
forte presença de imagens é um avanço no mercado editorial de MD para o ensino de PLE, mas a falta de contextualização entre imagens, textos e itens lexicais e gramaticais confere-lhe um caráter não comunicativo, no máximo comunicativizado, nas palavras de Almeida Filho.

Nas páginas 1 e 2 do livro de Lima, Iunes e Leite (2003) encontramos o padrão de todo o livro, que é a construção multimodal não com base em material autêntico, mas em ilustrações feitas exclusivamente para o material. A página 1 traz um texto sobre telecomunicações sem que haja introdução prévia ao tema, o que seria necessário, uma vez que se trata de material para iniciantes. As imagens relacionadas ao texto ilustram bem o contexto. Não há, no restante da unidade, um contexto comunicativo elaborado que promova interação, mas sim a forma. A imagem presente no canto direito da página 2, com o intuito de ilustrar os cumprimentos dos participantes representados, situa-os no contexto de saudações e cumprimentos, mas não os relaciona, não os une por um vetor, uma vez que seus olhos estão retorcidos, cada um em uma direção, o que não confere com a disposição de cada participante - em pé um diante do outro. Essa nuance nos remete à abordagem gramaticalista, cujo foco na forma tira a atenção e o enfoque dos outros modos de representação semiótica que não dão ênfase inicial à estrutura gramatical.

\section{Considerações finais}

O tema é amplo e ainda há muito a se fazer, mas demos um importante passo. A linguagem é social e multifacetada, e suas realizações de significado não ocorrem por apenas um meio semiótico, mas por vários, que, combinados, perfazem a linguagem como multissemiótica, ou multimodal, característica inerente ao próprio processo de comunicação humana. Portanto, é preciso que o professor de línguas esteja atento ao fato de que as escolhas de imagens, textos e quaisquer outros recursos constituintes dos materiais didáticos veiculam ideologias e relações de poder presentes na(s) sociedade(s). Nesse sentido, o próprio professor, ao produzir material, deve estar atento, pois suas escolhas refletirão a premissa supracitada. 


\section{Referências}

ALMEIDA, D. B. Do texto às imagens: as novas fronteiras do letramento visual. In: ROCA, P. et alii. Linguística Aplicada: um caminho com diferentes acessos. São Paulo: Contexto, 2009.

ALMEIDA FILHO, J. C. P. Linguística Aplicada, ensino de línguas e comunicação. Campinas: Ponte, 2005.

A abordagem orientadora da ação do professor. In: ALMEIDA FILHO, J. C. P. Parâmetros atuais para o ensino de Português Língua Estrangeira. Campinas: Pontes, 1998.

Análise de abordagem como procedimento fundador de autoconhecimento e mudança para o professor de língua estrangeira. In: ALMEIDA FILHO, J. C. P. O professor de língua estrangeira em formação. 2. ed. Campinas: Pontes, 2005.

. A produção de projetos iniciais sobre o processo de ensinoaprendizagem de línguas. In: ALMEIDA FILHO, J. C. P.; CUNHA, M. J. Projetos iniciais em português para falantes de outras línguas. Campinas: Pontes, 2007.

. Dimensões comunicativas no ensino de línguas. Campinas: Pontes, 1993.

BAUMAN, Z. Globalização: as consequências humanas. Tradução de Marcus Penchel. Rio de Janeiro: Jorge Zahar Ed., 1999.

BOGDAN, R. C.; BIKLEN, S. K. Qualitative research for education: an introduction to theory and methods. Needham Heights, MA: Allyn \& Bacon, 1998.

BRASIL. Secretaria da Educação Fundamental. Parâmetros Curriculares Nacionais: terceiro e quarto ciclos do ensino fundamental: língua estrangeira. Brasília: MEC/SEF, 1998. 
BROWN, H. D. Principles of language learning and teaching. 4 ed. [S.1.]: Ed. Longman, 2000.

CANALE, M.; SWAIN, M. Theoretical bases of communicative approaches to second language teaching and testing. Applied Linguistics, v. 1, 1980.

COSTA, S. A dimensão intercultural no ensino de português para estrangeiros. Dissertação (Mestrado em Linguística Aplicada) Instituto de Letras, Universidade de Brasília, Brasília, 1994.

CELCE-MURCIA, M. Language teaching approaches: an overview. In: _. Teaching English as a second or foreign language. 2 ed. Heinle \& Heinle Publishers, 1991.

DAMIANOVIC, Maria Cristina. Material didático: de um mapa de busca ao tesouro a um artefato de mediação In: (Org.). Material didático: elaboração e avaliação. Taubaté: Cabral Editora e Livraria Universitária, 2007. p. 199-214.

DESCARDECI, M. A. A. Souza. Ler o mundo: um olhar através da semiótica social. Educação Temática Digital, Campinas, v. 3, n. 2, p. 19-26, Unicamp, jun. 2002.

DIONÍSIO, A. P. Gêneros multimodais e multiletramento. In: BRITO, S. et al. Gêneros textuais: reflexões e ensino. 2. ed. Rio de Janeiro: Lucerna, 2006.

FAIRCLOUGH, Norman. Discurso e mudança social. Coordenadora da tradução: Izabel Magalhães. Brasília: Editora Universidade de Brasília, 2001.

FERRAZ, Janaína A. A identidade do brasileiro: um enfoque multimodal. Dissertação (Mestrado em Linguística) - Instituto de Letras, Universidade de Brasília, Brasília, 2005.

Multimodalidade e formação identitária: o brasileiro em materiais didáticos de PLE. In: VIEIRA, Josênia et al. Reflexões sobre 
Análise de textos multimodais...

a língua portuguesa: uma abordagem multimodal. Petrópolis: Vozes, 2007.

FIELD, Mary Lee. Componentes visuais e a compreensão de textos. São Paulo: SBS, 2004.

FLICK, U. Uma introdução à pesquisa qualitativa. Porto Alegre: Bookman, 2004.

FREITAS, M. C. M. A. Duas abordagens em harmonia ou conflito? O professor e o MD em um curso de formação de E/LE. Dissertação (Mestrado em Linguística Aplicada) - Universidade de Brasília, Brasília, UnB, 2008.

GERGEN, M.; GERGEN, J. Investigação qualitativa: tensões e transformações. IN: DENZIN, N. K.; LINCOLN, Y. S. (Org.). $O$ planejamento de pesquisa qualitativa: teorias e abordagens. Porto Alegre: Artmed, 2006.

GERMAIN, C. Evolution de l'enseignement des langues: 5000 ans d'histoire. Paris: Clé International, 1993 (Col. Didactique des langues étrangères).

GOTTHEIM, L. Materiais didáticos de português do Brasil para estrangeiros: roteiro de material de ensino de base cultural para um curso de PE (SBPC99). In: Linha D’água, Humanitas, São Paulo, APLL, Número Especial, p. 91-107, 2000.

GOTTHEIM, L. A gênese da composição de um material didático para ensino-aprendizagem de português como segunda língua. Tese (Doutorado em Linguística Aplicada) - Universidade Estadual de Campinas, Campinas, 2007.

KRESS, Gunther; VAN LEEUWWEN, Theo. Reading images: the grammar of visual design. Londres: Routledge, 1996.

Multimodal discourse: the modes and media of contemporary communication. London: Arnold, 2000. 
Multimodal discourse: the modes and media of contemporary communication. London: Arnold, 2001.

KRESS, G.; LEITE-GARCÍA, R.; VAN LEEUWEN, T. Semiótica discursiva. In: El discurso como estructura y processo. estudios del discurso: introducción multidisciplinaria. v. 1. Barcelona: Gedisa Editorial, 2000.

KRESS, G. C.; JEWITT, Ogburn, J.; TSATSARELIS, C. Multimodal teaching and learning: the rhetorics of the Sciences classroom. London: Continuum, 2001.

LEFFA, Vilson J. Metodologia do ensino de línguas. In BOHN, Hilário. I.; VANDRESEN, P. Tópicos em Linguística Aplicada: o ensino de línguas estrangeiras. Florianópolis: Editora da UFSC, 1988.

LIMA, E. E. O. F. et al. Diálogo Brasil: curso intensivo de Português para estrangeiros. São Paulo: EPU, 2003.

. Português via Brasil: um curso avançado para estrangeiros. Edição Revista e Ampliada. São Paulo: EPU, 2005.

MAYER, Richard. Multimedia learning. Cambridge: Cambridge University Press, 2001.

MENDES, E. Aprender a língua, aprendendo a cultura: uma proposta para o ensino de Português Língua Estrangeira. In: SANTOS, P. et al. Tópicos em português língua estrangeira. Brasília: Editora Universidade de Brasília, 2002.

MOITA LOPES, Luis Paulo. Uma Linguística Aplicada mestiça e ideológica: interrogando o campo como linguista aplicado. In:

(Org.). Por uma Linguística Aplicada indisciplinar. São Paulo: Parábola, 2006.

. Linguística Aplicada como espaço e vida contemporânea: problematização dos construtos que têm orientado a pesquisa. In: 
(Org.). Por uma Linguística Aplicada indisciplinar. São Paulo: Parábola, 2006.

NIEDERAUER, Márcia Elenita. Os recursos multissemióticos no material didático de PLE: cada vez mais coloridos, mas invisíveis aos olhos do professor. Desempenho, n. 3, 2004.

PONCE, M. H. et al. Bem vindo! A Língua Portuguesa no mundo da comunicação. Ed. Atualizada. São Paulo: SBS, 2004.

PRABHU, N. S. Second language pedagogy. Oxford: Oxford University Press, 1987.

RICHARDS, J. C.; RODGERS, T. S. Approaches and methods in language teaching. Cambridge: Cambridge University Press, 1986.

SILVEIRA, Regina. C. P. Aspectos da identidade cultural brasileira para uma perspectiva interculturalista no ensino/aprendizagem de Português Língua Estrangeira. In: estrangeira: perspectivas. São Paulo: Cortez, 1998

STURKEN, M.; CARTWRIGHT, L. Practices of looking: an introduction to visual culture. Oxford: Oxford University Press, 2001.

TAYLOR, S. J.; ROBERT, B. Introduction to qualitative research methods: a guidebook and resource. New York: John Wiley \& Son, 1998.

VAN LEEUWEN, T. Introduction to Social Semiotics. New York: Routledge, 2005.

VIEIRA, J. et al. Reflexões sobre a língua portuguesa: uma abordagem multimodal. Petrópolis: Vozes, 2007.

WIDDOWSON, H. G. O ensino de línguas para a comunicação. 2. ed. Tradução de José Carlos P. de Almeida Filho. Campinas: Pontes, 1998. 
Giuliano Pereira de Oliveira Castro Recebido em: 09/03/2016 Aceito em: 16/06/2016

Title: Analysis of multimodal texts in Portuguese as a Foreign Language coursebook covers 